\title{
Composição químico-bromatológica e degradabilidade in situ de capim- Marandu em sistemas silvipastoris formados por babaçu e em monocultivo
}

\author{
Chemical Composition and bromatologic degradability in situ of Marandu grass in \\ silvopastoral systems formed by babassu and monoculture systems
}

\author{
ARAÚJO, Ricardo Alves de ${ }^{1 *}$; RODRIGUES, Rosane Claúdia ${ }^{2}$; COSTA, Clésio dos \\ Santos $^{2}$; SANTOS, Francisco Naysson Sousa ${ }^{1}$ COSTA, Francivaldo Oliveira ${ }^{2}$; LIMA, \\ Antonio José Temístocles de ${ }^{2}$; SILVA, Ivone Rodrigues da ${ }^{2}$; RODRIGUES, Marcônio \\ Martins $^{2}$
}

\footnotetext{
${ }^{1}$ Universidade Federal do Ceará, Centro de Ciências Agrárias e Ambientais, Departamento de Zootecnia, Fortaleza, Ceará, Brasil.

${ }^{2}$ Universidade Federal do Maranhão, Centro de Ciências Agrárias e Ambientais, Departamento de Zootecnia, Chapadinha, Maranhão, Brasil.

*Endereço para correspondência: ricardo_zoo@hotmail.com
}

\section{RESUMO}

Objetivou-se com o presente trabalho avaliar a degradabilidade in situ da matéria seca (MS) e a composição químico-bromatológica dos componentes morfológicos folha e colmo da Urochloa brizantha cv. Marandu em sistemas silvipastoris compostos por palmeiras de babaçu (Attalea speciosa) e em monocultivo na região Pré-Amazônica Maranhense. Foi utilizado o delineamento inteiramente casualizado com 0 , 80, 131, 160 palmeiras adultas.ha ${ }^{-1}$, caracterizando monocultura (Mono), baixa densidade de palmeiras (BDP), média densidade de palmeiras (MDP) e alta densidade de palmeiras (ADP) durante os períodos chuvoso e seco. Foram colhidas amostras representativas de cada um dos sistemas silvipastoris, utilizando quadrados de $0,25 \mathrm{~m}^{2}$. Eles foram posicionados de forma aleatória em pontos representativos dos pastos no momento da amostragem e as plantas contidas no interior de cada quadrado foram cortadas a cada 28 dias, rente ao solo. As amostras, após pesadas, foram separadas em componentes morfológicos folhas e colmos, levadas a estufa e feitas as análise laboratoriais. $\mathrm{O}$ sombreamento proporcionado pelas palmeiras de babaçu influenciou o valor nutritivo do capimMarandu em ambos os períodos de avaliação, principalmente no teor de proteína bruta nos sistemas silvipastoris, observou-se que a degradabilidade in situ da matéria seca das folhas foi maior que o colmo e que houve pouca influência dos sistemas pastoris nos parâmetros de degradabilidade.

Palavras-chave: colmo, degradabilidade, folha, sombreamento

\section{SUMMARY}

The objective of the present work was to evaluate the in situ degradability of dry matter (DM) and the composition of components morphological leaf and stem of Urochloa brizantha cv. Marandu in silvopastoral systems composed of palms of babassu palm (Attalea speciosa) and monoculture systems in region Pre-Amazon Maranhense. The experimental design was completely randomized with $0,80,131,160$ adult palms.ha ${ }^{-1}$, characterizing monoculture (Mono), low density of palm trees (LDP), average density of palm trees (ADP) and high density of palm trees (HDP) during the periods rainy and dry. Representative samples were taken from each one of the systems silvipastoris, using squares of $0.25 \mathrm{~m}^{2}$. They were positioned at random in representative points of pastures at the time of sampling and the plants contained inside of each square were cut every 28 days, flush to the ground. The samples, after heavy, morphological components were separated in leaves and culms, carried the oven and made the laboratory 
analysis. The shade provided by trees of babassu influenced the nutritive value of Marandu grass both evaluation periods, mainly in crude protein content in silvopastoral systems, it has been observed that the in situ degradability of dry matter of the leaves was greater than the stem and that there was little influence of grazing systems in parameters of degradability.

Key words: culm, degradability, leaf, shading

\section{INTRODUÇÃO}

Os sistemas agroflorestais, em suas diferentes modalidades, agrossilviculturais, agrossilvispastoris e silvipastoris, são opções agroecológicas que incluem em seus conceitos referências aos principais componentes da sustentabilidade, ou seja, o econômico, o social e o ambiental (MACEDO, 2009).

A escolha das espécies que compõe o sistema de integração tem relação direta com a viabilidade da atividade. As espécies arbóreas devem ter rápido estabelecimento e copa pouco adensada, e as espécies agrícolas e forrageiras devem apresentar tolerância às condições do cultivo, pois a concorrência por luminosidade, água e nutrientes pode afetar o componente agrícola e resultar em perdas de produtividade (VIEIRA \& SCHUMACHER, 2011).

De acordo com as características de cada ecossistema as matas nativas podem adaptar-se aos chamados sistemas silvipastoris naturais, preservando assim árvores comuns de determinadas regiões. No estado do Maranhão, por exemplo, o consórcio de palmeiras do babaçu (Attalea speciosa Mart.) adultas, com pastagens, tem sido chamado 'sistema silvipastoril tradicional'. Essa palmeira se destaca em floresta de mata seca da Amazônia Oriental, principalmente no Maranhão, onde se concentram cerca de $53 \%$ dos babaçuais do território brasileiro. Apesar da grande importância que a palmeira de babaçu tem no Estado, pouco se sabe sobre as propriedades ecológicas desta, bem como dos seus efeitos na vegetação e solo, seu manejo eficiente ou sobre as densidades ideais de palmeiras dentro da pastagem.

Combinações de gramíneas cultivadas com o babaçu pode ser uma estratégia econômica e ambientalmente viável para a agropecuária, pois se trata de uma espécie nativa de caráter pioneira, de fácil manutenção, sem a necessidade de gastos com a introdução de mudas, manutenção do bosque, resistente aos incêndios além de não necessitar isolamento da área de plantio durante os primeiros anos de estabelecimento.

Diante do exposto e considerando-se as adaptações das gramíneas em relação ao sombreamento em sistemas silvipastoris, objetivou-se, nesse trabalho, avaliar a influência de diferentes densidades de palmeiras de babaçu em sistemas agroflorestais na degradabilidade da matéria seca e composição químicobromatológica dos componentes morfológicos folha e colmo da Urochloa brizantha cv. Marandu em sistemas silvipastoris compostos por palmeiras de babaçu (Attalea speciosa) e em monocultivo na Pré-Amazônica Maranhense.

\section{MATERIAL E MÉTODOS}

O experimento foi conduzido na Fazenda Água-Viva, no município de MatinhaMA, Região Pré-Amazônica Maranhense, tendo como posição geográfica $45^{\circ} 0^{\prime} 40,9^{\prime \prime} \mathrm{W}$ de longitude e $03^{\circ} 06^{\prime} 55,5^{\prime \prime} \mathrm{S}$ de latitude. A espécie forrageira utilizada foi a Urochloa brizantha cv. Marandu e a espécie arbórea a palmeira de babaçu Attalea speciosa Martius que já se encontravam estabelecidas na propriedade. Os 
Rev. Bras. Saúde Prod. Anim., Salvador, v.17, n.3, p.401-412 jul./set., $2016 \quad \underline{\text { http://www.rbspa.ufba.br }}$ ISSN 15199940

sistemas avaliados foram: monocultura de capim-Marandu e três densidades de palmeiras de babaçu mais capimMarandu (SSP), 0, 80, 131, 160 palmeiras adultas.ha ${ }^{-1}$, caracterizando monocultura (mono), baixa densidade (BDP), média densidade (MDP) e alta densidade de palmeiras (ADP), respectivamente.

Os dados referentes às médias da precipitação pluviométrica mensal calculada a partir de uma série de dados de 30 anos e durante o período experimental estão representados na Figura 1.

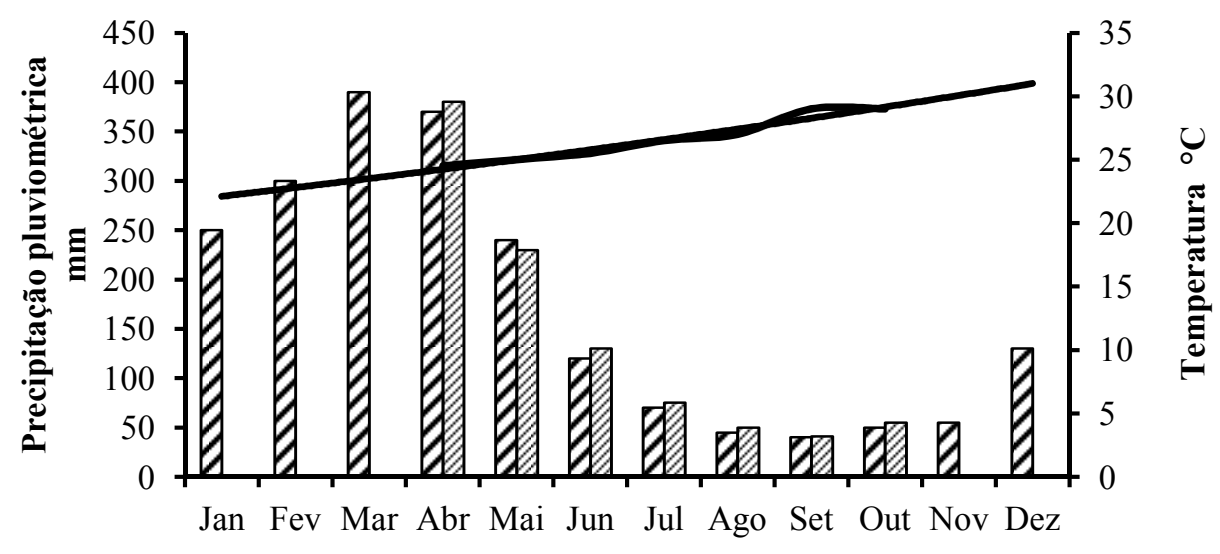

Meses

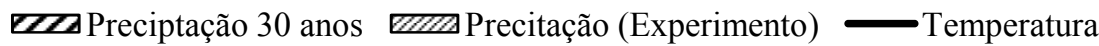

Fonte: INMET (Adaptado)

Figura 1. Médias mensais da precipitação pluviométrica mensal acumulada em médias climatológicas calculadas a partir de uma série de dados de 30 anos observados e durante os meses experimentais no ano de 2013

A precipitação pluviométrica anual variou em torno de $2.000 \mathrm{~mm}$ anuais, sendo que a maior concentração durante o período experimental ocorreu entre os meses de Abril a Junho. Já em relação à temperatura desta região, observa-se que a máxima e a mínima, ficaram em torno de $32^{\circ}$ a $23^{\circ} \mathrm{C}$ respectivamente.

Antes do estabelecimento do experimento foram realizadas amostragens para caracterização da fertilidade do solo nas camadas $0-20 \mathrm{~cm}$ e em seguida realizadas as correções da acidez do solo com base nos dados da análise.

As avaliações de massa de forragem foram realizadas a cada 28 dias, durante sete ciclos. Foram colhidas amostras representativas dos piquetes, utilizando quadrados de $0,25 \mathrm{~m}^{2}$, eles foram posicionados de forma aleatória em pontos representativos da pastagem e a forragem contida no interior de cada quadrado foram cortadas rente ao solo. As amostras de folha e colmo foram agrupadas em amostras que representaram os períodos chuvoso e seco. O teor de matéria seca (MS), proteína bruta (PB) e o pH foram calculados segundo recomendações da AOAC (1990), a fibra em detergente neutro (FDN) e ácido (FDA) seguindo os procedimentos de Van Soest et al. (1994). 
A hemicelulose foi calculada pela diferença entre o FDN e FDA e o teor de celulose pela diferença entre o FDA e a lignina.

Para avaliação da degradabilidade in situ da MS foram utilizados sacos de náilon com dimensões $12 \times 8 \mathrm{~cm}$ e porosidade $50 \mu \mathrm{m}$, contendo $4 \mathrm{~g}$ de amostra, de acordo com relação de $42 \mathrm{mg} / \mathrm{cm}^{2}$ adotada por Campos et al. (2011) e incubados no rúmen de um bovino fistulado nos tempos 6, 24 e 72h (MOREIRA FILHO et al., 2013). Foram estimados os parâmetros de degradação in situ $(a, b$ e c) e a degradabilidade potencial da MS, PB e FDN, pelo modelo proposto por Sampaio (1995), a partir de simplificação do modelo exponencial de Ørskov \& McDonald (1979).

Os dados foram agrupados em dois períodos: período chuvoso (de abril a junho/julho de 2013) e período seco (de junho/julho de2013 a outubro de 2013). Inicialmente os dados foram submetidos a teste de normalidade (Crame- Von Misses) e homocedasticidade (Levene) e, atendida as pressuposições, foram submetidas à análise de variância pelo teste $\mathrm{F}$, e no caso de diferença significativa, procedeu-se a comparação de médias pelo teste de Tukey a 5\% de probabilidade. As análises estatísticas foram realizadas pelo PROC GLM do SAS 9.0 (2002). Para avaliação da degradação, foi realizada estatística descritiva para média, segundo o PROC MEANS do SAS (2002). Os parâmetros $a, b$ e c e as curvas de degradação in situ foram obtidos segundo a equação exponencial, proposta por Ørskov \& Mcdonald (1979) e determinados segundo o método de Gauss-Newton por meio do PROC NLIN do SAS (2002). O uso do bovino fistulado foi aprovado pelo Comitê de Ética e Biossegurança sob o número: (23115.011059/2015-26).

\section{RESULTADOS E DISCUSSÃO}

$\mathrm{O}$ teor de PB das folhas foi maior que a fração colmo em todos os sistemas $(\mathrm{P}<0,05)$, e ao comparar os ambientes pastoris dentro de cada período percebese que o sistema de ADP apresentou uma forragem com maior teor proteico em ambas os componentes morfológicos (Tabela 1).

A proteína bruta aumentou com o sombreamento, pois como esse produto é considerado um composto orgânico complexo, portanto, dependente dos nutrientes do solo e o sombreamento favorece a mineralização devido um microclima mais agradável no solo, observou-se esse aumento em seu teor. Esses valores observados discordam de Moura (2004), no qual observou que em áreas com grandes densidades de babaçuais há um efeito linear na redução da porcentagem de proteína à medida que a densidade aumenta, indicando uma possível competição por água e nutrientes, e tal efeito não aconteceu neste trabalho.

Com relação à influência da palmeira sobre características de solo, Rodrigues et al. (2015), investigaram as características microbiológicas do solo em sistemas silvipastoris formado por capim-Marandu com diferentes densidades de palmeira e observaram que o sistema silvipastoril favoreceu a biomassa e atividade microbiana do solo, pois verificaram que o $\mathrm{C}$ microbiano, $\mathrm{N}$ microbiano, relação biomassa microbiana do solo e C orgânico apresentaram valores mais elevados em solos com alta densidade da palmeira de babaçu, o que favorece a mineralização do solo, aumentando sua fertilidade. 
Rev. Bras. Saúde Prod. Anim., Salvador, v.17, n.3, p.401-412 jul./set., $2016 \quad \underline{\text { http://www.rbspa.ufba.br }}$ ISSN 15199940

Tabela 1. Composição químico-bromatológica das frações folhas e colmo do capimMarandu em sistemas silvipastoris e monocultura no período chuvoso

\begin{tabular}{|c|c|c|c|c|}
\hline \multirow{2}{*}{ Sistemas } & \multicolumn{2}{|c|}{ Proteína bruta (\% MS) } & \multicolumn{2}{|c|}{ Fibra em detergente neutro (\%MS } \\
\hline & Folha & Colmo & Folha & Colmo \\
\hline Mono $^{1}$ & $7,58^{\mathrm{Ba}}$ & $5,83^{\mathrm{Bb}}$ & $57,63^{\mathrm{Ab}}$ & $72,02^{\mathrm{Aa}}$ \\
\hline $\mathrm{BDP}^{2}$ & $8,75^{\mathrm{Ba}}$ & $6,42^{\mathrm{Ab}}$ & $52,60^{\mathrm{Ab}}$ & $67,21^{\mathrm{Aa}}$ \\
\hline $\mathrm{MDP}^{3}$ & $8,58^{\mathrm{Ba}}$ & $6,17^{\mathrm{Ab}}$ & $56,67^{\mathrm{Ab}}$ & $72,80^{\mathrm{Aa}}$ \\
\hline $\mathrm{ADP}^{4}$ & $11,09^{\mathrm{Aa}}$ & $7,29^{\mathrm{Ab}}$ & $52,00^{\mathrm{Ab}}$ & $66,67^{\mathrm{Aa}}$ \\
\hline \multirow[t]{3}{*}{ CV (\%) } & \multicolumn{2}{|c|}{29,13} & \multicolumn{2}{|c|}{18,55} \\
\hline & \multicolumn{2}{|c|}{ Fibra em detergente ácido (\%MS) } & \multicolumn{2}{|c|}{ Lignina $(\% \mathrm{MS})$} \\
\hline & Folha & Colmo & Folha & Colmo \\
\hline Mono & $50,34^{\mathrm{Aa}}$ & $55,61^{\mathrm{Aa}}$ & $7,15^{\mathrm{Aa}}$ & $8,48^{\mathrm{Aa}}$ \\
\hline BDP & $51,79^{\mathrm{Aa}}$ & $54,07^{\mathrm{Aa}}$ & $9,99^{\mathrm{Aa}}$ & $6,45^{\mathrm{Aa}}$ \\
\hline MDP & $49,16^{\mathrm{Aa}}$ & $59,36^{\text {Aa }}$ & $8,07^{\mathrm{Aa}}$ & $10,11^{\mathrm{Aa}}$ \\
\hline ADP & $51,90^{\mathrm{Aa}}$ & $54,15^{\mathrm{Aa}}$ & $8,79^{\mathrm{Aa}}$ & $9,77^{\mathrm{Aa}}$ \\
\hline \multirow[t]{3}{*}{ CV (\%) } & \multicolumn{2}{|c|}{10,99} & \multicolumn{2}{|c|}{33,78} \\
\hline & \multicolumn{2}{|c|}{ Celulose (\%MS) } & \multicolumn{2}{|c|}{ Hemicelulose (\%MS) } \\
\hline & Folha & Colmo & Folha & Colmo \\
\hline Mono & $43,19^{\mathrm{Aa}}$ & $43,19^{\mathrm{Aa}}$ & $17,29^{\mathrm{Ba}}$ & $16,41^{\mathrm{Aa}}$ \\
\hline $\mathrm{BDP}$ & $27,23^{\mathrm{Aa}}$ & $27,23^{\mathrm{Aa}}$ & $26,07^{\mathrm{Aa}}$ & $13,14^{\mathrm{Aa}}$ \\
\hline MDP & $41,09^{\mathrm{Aa}}$ & $41,09^{\mathrm{Aa}}$ & $17,50^{\mathrm{Ba}}$ & $13,44^{\mathrm{Aa}}$ \\
\hline ADP & $43,10^{\mathrm{Aa}}$ & $43,10^{\mathrm{Aa}}$ & $18,10^{\mathrm{Ba}}$ & $12,52^{\mathrm{Aa}}$ \\
\hline CV (\%) & \multicolumn{2}{|c|}{9,13} & \multicolumn{2}{|c|}{10,12} \\
\hline
\end{tabular}

Médias nas colunas seguidas pela mesma letra maiúscula não diferem entre si ( $\mathrm{P}>0,05)$.

Médias nas linhas seguidas pela mesma letra minúscula não diferem entre si $(\mathrm{P}>0,05)$.

${ }^{1}$ monocultivo, ${ }^{2} 80$ palmeiras.ha ${ }^{-1},{ }^{3} 131$ palmeiras.ha ${ }^{-1},{ }^{4} 160$ palmeiras.ha ${ }^{-1}$.

Segundo Moreira Filho et al. (2013), os maiores teores de $\mathrm{PB}$ nas plantas sombreadas estão ligados ao maior tamanho das células, o que resulta em maior conteúdo celular e, consequentemente, maiores teores de PB. Outro mecanismo que pode ter contribuído para os maiores teores de PB está relacionado ao atraso no desenvolvimento ontogenético de plantas cultivadas à sombra mais intensa. Neste caso, as forrageiras tendem a ser mais jovem fisiologicamente, o que prolonga a fase vegetativa juvenil e permite a manutenção dos níveis metabólicos mais elevados por maior período de tempo, conforme resultados discutidos por Sousa et al. (2010).
Tosta et al. (2015) avaliando o valor nutritivo do capim-Marandu em diferentes localizações dentro do pasto em sistemas silvipastoris com diferentes densidades da palmeira de babaçu verificou efeito da interação densidade de palmeira e localização dentro do pasto $(\mathrm{P}<0,05)$ apenas para os teores de PB e MS. Desdobrando o efeito da localização no pasto dentro das densidades de palmeira para a variável $\mathrm{PB}$, verificou-se efeito apenas para as localizações dentro do pasto, onde se observou que consistentemente, a forragem sem interferência da sombra apresentou os maiores teores de PB em todas as densidades de palmeiras em relação à localização com sombra.

O teor de FDN foi superior na fração colmo em relação às folhas em todos os 
ambientes $(\mathrm{P}<0,05)$, sendo que não houve diferença entre os sistemas para as duas variáveis (folha e colmo). Esses resultados estão de acordo com os reportados por Paciullo et al. (2008), em que, para diferentes espécies de forrageiras, observou-se o melhor valor nutritivo das lâminas foliares em comparação ao do colmo.

Não houve variação no teor de FDA e lignina durante $\mathrm{o}$ período chuvoso $(\mathrm{P}>0,05)$. Não há um consenso sobre o efeito do sombreamento na concentração de lignina nas forrageiras, plantas cultivadas na sombra tendem a ter maior teor de lignina quando comparadas às em monocultivo, porém plantas sombreadas possuem menor idade fisiológica o que pode resultar em menores teores de lignina e nesse estudo essa variável não foi influenciada pelas densidades de palmeiras, fato mais curioso ainda é que o teor desse composto foi igual para ambos os componentes estruturais avaliados.

$\mathrm{O}$ teor de celulose foi igual para ambos os componentes e não sofreram influencia das densidades de palmeiras e no sistema de monocultivo $(\mathrm{P}>0,05)$. Este resultado demonstra que os babaçuais, independente da densidade, não interferiram de forma significativa nos teores dos carboidratos fibrosos (celulose e hemicelulose) e da lignina, tanto no nas folhas, quanto no colmo, mantendo a mesma composição.

Não houve variação no teor de hemicelulose entre os componentes morfológicos avaliados $(\mathrm{P}>0,05)$. As plantas do sistema de BDP tiveram um maior conteúdo de hemicelulose nas folhas $(\mathrm{P}<0,05)$, e em relação ao colmo seus valores não foram influenciados pelas densidades de palmeiras. A variação no teor de $\mathrm{PB}$ observado nas folhas dos sistemas silvipastoris pode ter influenciado positivamente nos resultados de hemicelulose, pois segundo Taiz \& Zeiger (2004), quando ocorre deficiência de nitrogênio, e ela se desenvolve lentamente, é possível que as plantas tenham caules pronunciadamente delgados e lenhosos, isso devido ao acúmulo de carboidratos em excesso, que não podem ser utilizados na síntese de aminoácidos ou de outros compostos nitrogenados.

Para o teor de $\mathrm{PB}$ não houve variação entre os componentes e densidades $(\mathrm{P}>0,05)$. Os valores de $\mathrm{PB}$ foram sempre inferiores a $7 \%$, e que segundo Lazzarini et al. (2009), sugeriram $70 \mathrm{~g}$ de $\mathrm{PB} / \mathrm{kg}$ de $\mathrm{MS}$, como mínimo para que não haja comprometimento do crescimento microbiano ruminal e, consequentemente, para que ocorra utilização eficiente dos carboidratos fibrosos da forragem basal, portanto o disponibilidade mínima para garantir o bom funcionamento dos microrganismos ruminais que ingeriram essa forragem durante esse período foi provavelmente garantido, algo incomum no período seco (Tabela 2).

$\mathrm{O}$ teor de FDN das folhas do capim no sistema de BDP foi inferior ao FDN do colmo $(\mathrm{P}<0,05)$. A concentração de fibra em detergente ácido foi maior no colmo $(\mathrm{P}>0,05)$, sendo que para as folhas não houve influência dos sistemas durante esse período, já na fração colmo observa-se um menor teor de FDA no capim dos sistemas de MDP e $\operatorname{ADP}(\mathrm{P}>0,05)$. $\mathrm{O}$ teor de lignina não variou e a celulose do colmo nas plantas da ADP foi superior as das folhas, sendo que na estrutura foliar o maior teor desse carboidrato estrutural foi observado nos sistemas de Mono, BDP e MDP ( $\mathrm{P}>0,05)$.

$\mathrm{O}$ teor de hemicelulose nas folhas dos sistemas de MDP e ADP foram superiores ao do colmo $(\mathrm{P}<0,05)$. A presença dos babaçuais não interferiu na hemicelulose das folhas e colmos. Segundo Sousa et al. (2010), em 
Rev. Bras. Saúde Prod. Anim., Salvador, v.17, n.3, p.401-412 jul./set., $2016 \quad \underline{\text { http://www.rbspa.ufba.br }}$ ISSN 15199940

condições de sombreamento natural o capim-Marandu possui a lignina menos entremeada com a hemicelulose e celulose. Nessa situação, a lignina possui uma maior proporção de siringaldeído, um monômero que se complexa menos com a hemicelulose e a celulose que a vanilina, caracterizando assim com uma fibra de melhor qualidade nutritiva.

Tabela 2. Composição químico-bromatológica das frações folhas e colmo do capimMarandu em sistemas silvipastoris e monocultura no período seco

\begin{tabular}{|c|c|c|c|c|}
\hline \multirow{2}{*}{ Sistemas } & \multicolumn{2}{|c|}{ Proteína bruta (\% MS) } & \multicolumn{2}{|c|}{ Fibra em detergente neutro $(\% \mathrm{MS})$} \\
\hline & Folha & Colmo & Folha & Colmo \\
\hline Mono $^{1}$ & $6,00^{\mathrm{Aa}}$ & $5,83^{\mathrm{Aa}}$ & $69,98^{\mathrm{Aa}}$ & $75,21^{\mathrm{ABa}}$ \\
\hline $\mathrm{BDP}^{2}$ & $6,58^{\mathrm{Aa}}$ & $5,83^{\mathrm{Aa}}$ & $65,54^{\mathrm{Ab}}$ & $76,02^{\mathrm{Aa}}$ \\
\hline $\mathrm{MDP}^{3}$ & $6,58^{\mathrm{Aa}}$ & $5,25^{\mathrm{Aa}}$ & $68,33^{\mathrm{Aa}}$ & $68,26^{\mathrm{Ba}}$ \\
\hline $\mathrm{ADP}^{4}$ & $6,33^{\mathrm{Aa}}$ & $5,25^{\mathrm{Aa}}$ & $67,85^{\mathrm{Aa}}$ & $73,20^{\mathrm{ABa}}$ \\
\hline \multirow[t]{3}{*}{ CV (\%) } & \multicolumn{2}{|c|}{28,69} & \multicolumn{2}{|c|}{5,29} \\
\hline & \multicolumn{2}{|c|}{ Fibra em detergente ácido (\%MS) } & \multicolumn{2}{|c|}{ Lignina (\%MS) } \\
\hline & Folha & Colmo & Folha & Colmo \\
\hline Mono & $50,34^{\mathrm{Ab}}$ & $60,25^{\mathrm{Aa}}$ & $6,90^{\mathrm{Aa}}$ & $10,83^{\mathrm{Aa}}$ \\
\hline BDP & $51,79^{\mathrm{Ab}}$ & $60,58^{\mathrm{Aa}}$ & $7,06^{\mathrm{Aa}}$ & $8,90^{\mathrm{Aa}}$ \\
\hline MDP & $49,16^{\mathrm{Ab}}$ & $54,50^{\mathrm{Ba}}$ & $9,40^{\mathrm{Aa}}$ & $10,66^{\mathrm{Aa}}$ \\
\hline ADP & $51,90^{\mathrm{Ab}}$ & $59,18^{\mathrm{ABa}}$ & $8,27^{\mathrm{Aa}}$ & $7,54^{\mathrm{Aa}}$ \\
\hline \multirow[t]{3}{*}{ CV $(\%)$} & \multicolumn{2}{|c|}{5,24} & \multicolumn{2}{|c|}{23,53} \\
\hline & \multicolumn{2}{|c|}{ Celulose (\%MS) } & \multicolumn{2}{|c|}{ Hemicelulose (\%MS) } \\
\hline & Folha & Colmo & Folha & Colmo \\
\hline Mono & $44,98^{\mathrm{Aa}}$ & $49,42^{\mathrm{Aa}}$ & $18,10^{\mathrm{Aa}}$ & $14,95^{\mathrm{Aa}}$ \\
\hline BDP & $39,76^{\mathrm{ABa}}$ & $51,68^{\mathrm{Aa}}$ & $18,72^{\mathrm{Aa}}$ & $15,43^{\mathrm{Aa}}$ \\
\hline MDP & $39,42^{\mathrm{ABa}}$ & $43,84^{\mathrm{Aa}}$ & $19,57^{\mathrm{Aa}}$ & $13,75^{\mathrm{Ba}}$ \\
\hline ADP & $28,94^{\mathrm{Bb}}$ & $49,84^{\mathrm{Aa}}$ & $18,69^{\mathrm{Aa}}$ & $14,02^{\mathrm{Ba}}$ \\
\hline CV (\%) & \multicolumn{2}{|c|}{19,21} & \multicolumn{2}{|c|}{14,26} \\
\hline
\end{tabular}

Médias nas colunas seguidas pela mesma letra maiúscula não diferem entre si $(\mathrm{P}>0,05)$

Médias nas linhas seguidas pela mesma letra minúscula não diferem entre si $(\mathrm{P}>0,05)$

${ }^{1}$ monocultivo, ${ }^{2} 80$ palmeiras.ha ${ }^{-1},{ }^{3} 131$ palmeiras.ha ${ }^{-1},{ }^{4} 160$ palmeiras.ha ${ }^{-1}$.

As variações nos teores de FDN, FDA e lignina parecem estar relacionadas à interação da percentagem de sombra com o estádio de maturidade da planta. Em condições de elevadas percentagens de sombreamento, as plantas tendem a estiolar com o avanço da maturidade, o que pode resultar em aumentos dos teores de fibra da forrageira. $\mathrm{O}$ estiolamento é uma estratégia da planta no qual há o aumento da sua estatura em busca por luminosidade, e esse aumento normalmente ocorre pelo alongamento do colmo.
Na Tabela 3 estão presentes os teores médios de desaparecimento da MS no maior tempo de incubação avaliado (72hs), de acordo com o a fração folha e colmo nos diferentes sistemas de avaliação e período.

No período chuvoso a fração folha apresentou valores significativos de desaparecimento nos sistemas de BDP e ADP, já os sistemas de monocultura e MDP não apresentaram diferença, tendo estes sistemas menor desaparecimento da matéria seca (DMS) da fração folha. O comportamento foi inverso para a 
Rev. Bras. Saúde Prod. Anim., Salvador, v.17, n.3, p.401-412 jul./set., $2016 \quad \underline{\text { http://www.rbspa.ufba.br }}$ ISSN 15199940

fração colmo, uma vez que seu maior desaparecimento foi no sistema MDP. Em relação ao desaparecimento da MS, ao comparar as duas frações, a folha apresentou maior DMS em todos os sistemas avaliados.

Analisando-se o período seco o sistema de BDP apresentou diferença dos outros sistemas avaliados quanto ao DMS da fração folha, sendo os sistemas de monocultura e MDP, não diferiram estatisticamente. Não houve efeito na degradabilidade do colmo no período $(\mathrm{P}>0,05)$ entre os sistemas avaliados. Segundo Van Soest (1994) em condições de temperaturas mais elevadas, como nos trópicos, a mais intensa atividade metabólica converte os produtos fotossintéticos rapidamente em componentes estruturais.

Tabela 3. Degradabilidade potencial das frações folhas e colmo do capim-Marandu em sistemas silvipastoris e monocultura nos períodos chuvoso e seco

\begin{tabular}{|c|c|c|c|c|}
\hline \multirow{2}{*}{ Sistemas } & \multicolumn{2}{|c|}{ Período chuvoso } & \multicolumn{2}{|c|}{ Período seco } \\
\hline & Folha (\%MS) & Colmo (\%MS) & Folha (\%MS) & Colmo (\%MS) \\
\hline Mono $^{1}$ & $70,04^{\mathrm{Ba}}$ & $57,01^{\mathrm{ABb}}$ & $72,92^{\mathrm{ABa}}$ & $54,21^{\mathrm{Ab}}$ \\
\hline $\mathrm{BDP}^{2}$ & $76,82^{\mathrm{Aa}}$ & $58,01^{\mathrm{ABb}}$ & $74,58^{\mathrm{Aa}}$ & $53,99^{\mathrm{Ab}}$ \\
\hline $\mathrm{MDP}^{3}$ & $72,76^{\mathrm{Ba}}$ & $59,25^{\mathrm{Ab}}$ & $72,72^{\mathrm{ABa}}$ & $53,78^{\mathrm{Ab}}$ \\
\hline $\mathrm{ADP}^{4}$ & $77,31^{\mathrm{Aa}}$ & $54,92^{\mathrm{Bb}}$ & $67,48^{\mathrm{Ba}}$ & $56,61^{\mathrm{Ab}}$ \\
\hline CV (\%) & \multicolumn{2}{|c|}{3,54} & \multicolumn{2}{|c|}{6,10} \\
\hline
\end{tabular}

Médias nas colunas seguidas pela mesma letra maiúscula não diferem entre si ( $\mathrm{P}>0,05)$

Médias nas linhas seguidas pela mesma letra minúscula não diferem entre si $(\mathrm{P}>0,05)$

${ }^{1}$ monocultivo, ${ }^{2} 80$ palmeiras.ha ${ }^{-1},{ }^{3} 131$ palmeiras.ha ${ }^{-1},{ }^{4} 160$ palmeiras.ha ${ }^{-1}$.

Analisando as frações (folha e colmo), entre os períodos, observa-se sempre um maior desaparecimento da folha em relação ao colmo.

Os parâmetros de degradação ruminal in situ da MS do capim-Marandu estudados no período chuvoso e seco nos diferentes tipos de sistemas estão apresentados na Tabela 4. As taxas de degradação estimadas pelo modelo de regressão não linear variaram $(\mathrm{P}<0,05)$ entre os períodos do ano e as frações avaliadas.

Observou-se maior fração solúvel (a') na fração folha para os sistemas de BDP e MDP, no entanto, os valores de taxa de degradação $(C)$ foram maiores no sistema de monocultivo com 2,22\%, sendo $55,85 \%$ superior em relação ao sistema ADP que apresentou menor $\mathrm{C}$ $\left(1,24 \% \cdot \mathrm{h}^{-1}\right)$, porém, neste sistema observou-se maior degradabilidade efetiva (DE), nas três taxas de passagens $2 \%(61,83), 5 \%(46,74), 8 \%$ $(41,45)$, valores estes influenciados pelo A, C e a fração solúvel (a), sendo o segundo maior parâmetro observado nos sistemas avaliados, foram nos sistemas de BDP, com 36,98\%.

A fração solúvel (a) corresponde à parte solúvel do alimento, mais as partículas eliminadas através da malha dos sacos, quando esses são imersos no líquido ruminal e, posteriormente, lavados em água corrente. Segundo Goes et al. (2012) o maior desaparecimento ruminal no tempo zero é devido á maior presença de compostos solúveis em água. A maior fração solúvel foi observado no tratamento de monocultura e maior fração degradável (b'), porém menor $\mathrm{C}$ e $\mathrm{DE}$, isso pode ser explicado tendo em vista que gramíneas submetidas a sombreamento apresentam como 
Rev. Bras. Saúde Prod. Anim., Salvador, v.17, n.3, p.401-412 jul./set., $2016 \quad \underline{\text { http://www.rbspa.ufba.br }}$ ISSN 15199940

mecanismo de adaptação o maior alongamento do colmo. Já o sistema de ADP apresentou maior $\mathrm{C}$ da $\mathrm{MS}$ com $3,42 \% / \mathrm{h}$ entre os sistemas avaliados. Em trabalho realizado por Goes et al. (2012), avaliando degradação ruminal da matéria seca e de proteína bruta de volumosos para bovinos, observaram valores semelhantes para $\mathrm{DE}$ do capimMarandu encontrados neste trabalho nas três taxas de passagens avaliadas 2\% $(41,42), 5 \%(54,12)$ e $8 \%(34,87)$, esses valores ficaram próximos aos resultados obtidos para colmo, nos diferente sistemas e períodos avaliados. Entretanto, os resultados obtidos neste trabalho foram superiores para a fração folha, independente do sistema e do período avaliado.

Tabela 4. Parâmetros de degradação ruminal in situ (a',b' e c) da MS e degradabilidade efetiva da MS nas taxas de passagem de 2, 5 e $8 \%$ /hora das frações folhas e colmo do capim-Marandu em sistemas silvipastoris e monocultura nos períodos chuvoso e seco

\begin{tabular}{|c|c|c|c|c|c|c|c|}
\hline \multirow{2}{*}{ Sistemas } & \multicolumn{7}{|c|}{ Folha (\%MS) Período chuvoso } \\
\hline & $\mathrm{a}^{\prime}$ & $\mathrm{b}^{\prime}$ & C. $10^{2}$ & R2 & DE2\% & DE $5 \%$ & DE8\% \\
\hline Mono $^{1}$ & 28,76 & 54,34 & 2,22 & 99,62 & 57,35 & 45,47 & 40,56 \\
\hline $\mathrm{BDP}^{2}$ & 33,87 & 66,15 & 1,44 & 99,95 & 61,56 & 51,75 & 47,06 \\
\hline $\mathrm{MDP}^{3}$ & 29,29 & 59,68 & 1,78 & 99,83 & 57,39 & 44,96 & 40,15 \\
\hline \multirow[t]{2}{*}{$\mathrm{ADP}^{4}$} & 30,45 & 68,64 & 1,24 & 99,6 & 61,83 & 46,74 & 41,45 \\
\hline & \multicolumn{7}{|c|}{ Colmo (\%MS) Período chuvoso } \\
\hline Mono & 28,75 & 45,41 & 1,04 & 91,18 & 44,29 & 36,57 & 33,97 \\
\hline BDP & 26,86 & 36,17 & 3,0 & 92,17 & 48,56 & 40,42 & 36,72 \\
\hline MDP & 25,88 & 40,87 & 2,5 & 99,18 & 48,59 & 39,5 & 35,61 \\
\hline \multirow[t]{2}{*}{ ADP } & 26,78 & 31,19 & 3,42 & 98,42 & 46,46 & 39,45 & 36,12 \\
\hline & \multicolumn{7}{|c|}{ Folha (\%MS) Período seco } \\
\hline Mono & 33,5 & 59,59 & 1,7 & 96,3 & 60,88 & 48,62 & 43,94 \\
\hline BDP & 34,09 & 45,77 & 0,62 & 99,62 & 56,36 & 46,65 & 42,84 \\
\hline MDP & 36,94 & 46,31 & 2,11 & 94,85 & 60,71 & 50,68 & 46,61 \\
\hline \multirow[t]{2}{*}{ ADP } & 30,73 & 41,31 & 3,15 & 86,51 & 56,00 & 46,7 & 42,4 \\
\hline & \multicolumn{7}{|c|}{ Colmo (\%MS) Período seco } \\
\hline Mono & 33,5 & 29,34 & 1,99 & 84,82 & 48,13 & 41,85 & 39,34 \\
\hline BDP & 33,9 & 23,36 & 3,13 & 90,69 & 48,15 & 42,89 & 40,47 \\
\hline MDP & 29,19 & 30,05 & 2,49 & 72,74 & 46,13 & 39,35 & 36,44 \\
\hline ADP & 27,4 & 32,37 & 3,37 & 57,61 & 47,71 & 40,43 & 36,99 \\
\hline
\end{tabular}

${ }^{1}$ Monocultivo, ${ }^{2} 80$ palmeiras.ha ${ }^{-1},{ }^{3} 131$ palmeiras.ha ${ }^{-1},{ }^{4} 160$ palmeiras.ha ${ }^{-1}$.

$\mathrm{a}=$ fração solúvel ou rapidamente degradável $(\%) ; \mathrm{b}=$ fração insolúvel ou lentamente degradável (\%); c $=$ taxa de degradação de $\mathrm{b}(\% / \mathrm{h})$; coeficiente de determinação $\left(\mathrm{R}^{2}\right)$, Digestibilidade Efetiva (DE para taxas de passagem de 2,5 e $8 \% \cdot \mathrm{h}^{-1}$.

Os valores de $\mathrm{C}$ e $\mathrm{DE}$ encontrados no sistema de BDP no período seco para a fração folha foram baixos, em relação ao Mono, MDP e ADP, no entanto, apresentou valores intermediários nos outros parâmetros avaliados.
O sistema de MDP obteve valores superiores de DE nas três taxas de passagens, entre os sistemas. A fração colmo no período seco, nos sistemas de monocultura e BDP, apresentaram maior DE nas taxas de passagens. Já o 
sistema de BDP apresentou dados intermediários dos parâmetros avaliados. Observa-se diminuição nos parâmetros $\mathrm{A}$ e $\mathrm{B}$ da fração folha e colmo de acordo com a mudança no período de avaliação.

A taxa de degradação (C) sofreu alteração entre as frações avaliadas, sendo que, o colmo apresenta maior taxa de degradação em relação às folhas, esse comportamento tende a ser o mesmo nos dois períodos avaliados, isso se deve principalmente ao tecido encontrado no colmo, consiste em uma fração altamente lignificada e de difícil degradação, que necessita de taxas elevadas de degradação com um tempo de permanência maior no rúmen do animal. Os efeitos negativos da presença de lignina na parede celular sobre a degradabilidade são maiores no caule. Isto é indicativo de que outros efeitos além da concentração de lignina estão associados à redução da degradabilidade. Segundo Brito et. al. (2003) a presença de lignina na forma condensada, associada a células com parede celular mais espessa, constitui-se na maior barreira para a digestão dos tecidos no caule. Esses valores podem ser explicados pela baixa DE do colmo, sendo sempre menor em relação á fração a folha independente do sistema e período avaliado.

Observa-se que para ambas os componentes morfológicos e em todas as densidades a DE tende a diminuir com o aumento na taxa de passagem, isso acontece devido à ação dos microrganismos ruminais serem afetadas pela permanência do material no rúmen, uma vez que, quanto menor a taxa de passagem desse material no rúmen maior a ação dos microrganismos ruminais, influenciando dessa forma a digestibilidade efetiva. A $\mathrm{DE}$ da fração folha foi sempre superior ao colmo, esses resultados comprovam que as folhas apesar de alguns casos não diferirem dos colmos em relação aos carboidratos estruturais, mas sua degradação é mais rápida. Tosta et al. (2015), avaliando a influência de diferentes densidades de palmeiras de babaçu sobre a degradabilidade do capim-Marandu, observaram que em todas as densidades o desaparecimento de MS em 96h para pastagens cultivadas em pleno sol ultrapassou o de pasto cultivado na sombra total.

Vale ressaltar que as palmeiras de babaçu do experimento eram consideradas adultas, com média geral de 7,5m a altura do fuste (base da copa), de forma que a arquitetura (forma de pirâmide invertida) não comprometeu a penetração de luz difusa no pasto. Estas condições permitiram a produção de um sombreamento menos intenso sobre a forrageira. Além disso, o rápido deslocamento da projeção de sombra sobre o dossel reduz o efeito da sombra sobre a fotossíntese.

O sombreamento proporcionado pelas palmeiras de babaçu influencia o valor nutritivo do capim-Marandu em ambos os períodos de avaliação, principalmente no teor de proteína bruta nos sistemas silvipastoris, observa-se que a degradabilidade in situ da matéria seca das folhas é maior que o colmo e que há pouca influência dos sistemas pastoris nos parâmetros de degradabilidade.

\section{REFERÊNCIAS}

ASSOCIATION OF OFFICIAL ANALYTICAL CHEMISTS -AOAC. Official methods of analysis. 15.ed. Virginia: 1298p, 1990. 
Rev. Bras. Saúde Prod. Anim., Salvador, v.17, n.3, p.401-412 jul./set., $2016 \quad$ http://www.rbspa.ufba.br ISSN 15199940

BRITO, C. J. F.A. de; RODELLA, R.A.; DESCHAMPS, F.C. Chemical profile of cell wall and its implications on Brachiaria brizantha and Brachiaria humidicola digestibility. Revista Brasileira de Zootecnia, v.32, n.8, p.1835-1844, 2003.

CAMPOS, M.M.; BORGES, A.L.C.C.; LOPES, F.C.F. ; PANCOTI, C.G.; REIS E SILVA, R. Degradabilidade in situ da cana-de-açúcar tratada ou não com óxido de cálcio, em novilhas leiteiras Holandês $x$ Gir. Arquivo Brasileiro de Medicina Veterinária e Zootecnia, v.63, n.6, p.1487-1492, 2011.

GOES, R.H.T.B.; TRAMONTINI, R.C.M.; CARDIM, S.T.; ALMEIDA, G.D.; RIBEIRO, J.; MOROTTI, F.; OLIVEIRA, L.A.; SILVA BRABES, K.C.S. Degradação ruminal da matéria seca e de proteína bruta de volumosos para bovinos. Revista Acadêmica de Ciências Agrárias e Ambientais, v.10, n.3, p.285-291, 2012.

LAZZARINI, I.; DETMANN, E.; SAMPAIO, C.B.I; PAULINO, M.F.; VALADARES FILHO, S.C.; SOUZA, M.A.; OLIVEIRA, F.A. Intake and digestibility in cattle fed low-quality tropical forage and supplemented with nitrogenous compounds. Revista Brasileira de Zootecnia, v.38, p.20212030, 2009.

MACEDO, M.C.M. Integração lavoura e pecuária: o estado da arte e inovações tecnológicas. Revista Brasileira de Zootecnia, v.38, p.133-146, 2009.

MOURA, E.G. Agroambientes de transição avaliados numa perspectiva da agricultura familiar entre a Amazônia e o Nordeste, diversidade e estrutura. In: Moura, E. G. (Ed.). Agroambientes de transição entre o trópico úmido e o semi-árido do Brasil. São Luís: UEMA, 2004. cap. 1, p.15-51.
MOREIRA FILHO, M.A.; ALVES, A.A.; VALE, G.E.S.; MOREIRA, A.L.; ROGÉRIO, M.C.P. Valor nutritivo do feno de restolho da cultura do milho amonizado com ureia. Revisa Ciência Agronômica, v.44, n.4, p.893-901, 2013.

ØRSKOV, E.R.; McDONALD, I. The estimation of protein degradability in the rumen from incubation measurements weighted according to rate of passage. Journal of Agricultural Science, v.92, p.499-503, 1979.

PACIULLO, D.S.C.; CAMPOS, N.R; GOMIDE, C.A.M.; CASTRO, C.R.T.; TAVELA, R.C.; ROSSIELLO, R.O.P. Crescimento do pasto de capimbraquiária influenciado pelo nível de sombreamento e pela estação do ano.

Pesquisa Agropecuária Brasileira, v.43, n.7, p.317-323, 2008.

RODRIGUES, R.C.; ARAUJO, R.A.; COSTA, C.S.; LIMA, J.T.; OLIVEIRA, M.E.; SANTOS, F.N.S.; ARAUJO, J.S.; ARAUJO, A.S.F. Soil microbial biomass in agroforestry system of Northeast Brazil. Tropical grasslands, v.3, p.41-48, 2015.

SAMPAIO, I.B.M.; PIKE, D. J; OWEN, E. Optimal design for studying dry matter degradation in the rumen. Arquivo

Brasileiro de Medicina Veterinária e Zootecnia, v.47, p.373-383, 1995.

SAS. SAS/STAT: user's guide statistics. Version 9.0. Cary, NC: SAS Institute, 2002.

SOUSA, L.F.; MAURÍCIO, R.M.; MOREIRA, G.R.M.; GONÇALVES, L.C.G.; BORGES, I.; PEREIRA, L.G.R. Nutritional evaluation of "Braquiarão" grass in association with Aroeira trees in a silvopastoral system. Agroforestry Systems, v.79, n.2, p.189-199, 2010. 
Rev. Bras. Saúde Prod. Anim., Salvador, v.17, n.3, p.401-412 jul./set., $2016 \quad \underline{\text { http://www.rbspa.ufba.br }}$ ISSN 15199940

TAIZ, L.; ZEIGER, E. Plant

Physiology. Redwood City, California:

The Benjamim/Cummings Publishing

Company Inc., 2004.

TOSTA, X.M.; RODRIGUES, R.C; SANCHES, S.S.C.; ARAÚJO, J.S.; LIMA JÚNIOR, A.S.; COSTA, C.S.; SANTOS, F.N.S.; JESUS, A.P.R.; SILVA, I.R.; COSTA, F.O.; SHIGAKI, F.; MENDES, S.S. Nutritive value and in situ rumen degradability of Marandu palisade grass at different locations within the pasture in a silvopastoral system with different babassu palm densities. Tropical Grasslands, v.3, n.3, p.187-193, 2015.

VAN SOEST, PJ. Nutritional ecology of the ruminant. 2 ed. Ithaca: Cornell University Press, 1994

VIEIRA, M.; SCHUMACHER, M.V.

Biomassa em povoamentos monoespecíficos e mistos de eucalipto e acácia negra e do milho em sistema agrosilvicultural. Cerne, v.17, p.259 265, 2011.

Data de recebimento: $13 / 10 / 2015$

Data de aprovação: 19/07/2016 